\title{
Global Diffusion of Innovation: An Empirical Comparison
}

\author{
HAREESH N RAMANATHAN \\ School of Industrial Fisheries \\ Cochin University of Science and Technology \\ Kochi-682016, Kerala \\ INDIA \\ PEARLY SAIRA CHACKO \\ Department of Management Studies \\ Toc H Institute of Science and Technology \\ Arakkunam-682313, Kerala \\ INDIA \\ BERISLAV ANDRLIC \\ Department of Social Sciences \\ Polytechnic in Pozega \\ Vukovarska 17, 34000 Požega \\ REPUBLIC OF CROATIA
}

\begin{abstract}
Globalization has strengthened the flow of information and technology across borders. Sophisticated technological advancements have enabled rapidity in innovation and instantaneous communications, thereby reaching a wider audience. The purpose of this study is to understand the relative position of the three major developing countries - namely Croatia, India, and Sri Lanka concerning their phases of adoption of innovation. The study followed a descriptive research design. Data was collected via Web forms using a questionnaire and was administered among the youth in the three countries. The respondents of the study were chosen via the Snowball sampling technique. A spatial map to visualize the proximal relationship between the three countries and the stages of adoption of innovation was created using Correspondence analysis. In comparison, the study found Indian students to be among the 'innovator' and 'early adopter' categories. Whereas Croatia was placed close to 'late majority and Sri Lanka was placed midway between 'early adopter' and 'early majority.
\end{abstract}

Key-Words: - Diffusion of Innovation, adopter categories, innovation, correspondence analysis, globalization Received: June 10, 2021. Revised: December 3, 2021. Accepted: January 15, 2022. Published: January 16, 2022.

\section{Introduction}

Why do some products succeed, and some products fail in the market despite being superior? Well, diffusion of innovation theory provides a framework about how a new product, service, or idea gradually trickles down through the societies and cultures, starting from its introduction into the market to its gradual adoption. The rate of adoption process varies between cultures and country to country.

In this 'boundaryless' age, with social media increasingly aiding the limitless flow of information and accessibility of new products, the adoption varies across countries. Numerous researches are available that reiterate the effect of culture on the diffusion process. The word culture is an expansive one, and it implies diverse meanings when used in a different context. For instance, organizational culture and national culture are different, and so is regional or geographical culture. There are many cross-cultural studies on diffusion; nonetheless, these studies focus on the cultural dimensions using Hofstede's cultural scale [26],[27]. The other most studied factor that was found to be true is the 
innovation attributes like compatibility, relative advantage, trail-ability, observability, and complexity as perceived by the society [37]. Research on the impact of the different adopter categories on the diffusion of new products' innovation is commonly found [12], [10].

Culture is predominantly labelled as the key driver to the global diffusion of innovation, yet some studies cite that wealth as a driver to the diffusion process [39]. The mean global take-off time varies between developed countries and developing countries, and this tie also varies between different product categories [7].

Technological developments play a central role in the economic development of a country. Globalization has, in a big way enhanced technology transfer and productivity and more significant employment opportunities [29]. Economic indicators like Real Gross Domestic Product (GDP) growth, household final consumption index, and consumer confidence talk a lot about the consumer's ability and willingness to purchase new products.

Globalization and technological advancements have increased the attractiveness of emerging nations for multinational firms. Global companies are eyeing the enormous potential of the developing world, and this has also led to joint collaborative efforts to reduce the risk [38].

In this research, the investigators review the relative position regarding the stages of diffusion of innovation in a multicultural context done among youths in three nations -namely Croatia, India, and Sri Lanka. The researcher sought to compare developing countries on different continents. Croatia is an open developing economy and is classified as an 'upper-middle-income country' whereas India and Sri Lanka are classified as 'lower-middle-income country' [43]. Correspondence analysis was used to plot the spatial map of the stages of innovation.

Culture is complex with many sub levels. It can be simply defined as 'shared beliefs, values, and assumptions of a group of people who learn from one another and teach to others that their behaviours, attitudes, and perspectives are the correct ways to think, act, and feel' [28]. Culture can be understood as mental programming with four layers - symbols, heroes, rituals and values; with values forming the inmost core of culture which in turn differentiates a group or society from another [13]. However, being multifaceted, culture can manifest in various ways. That means it can sometimes act as an enabler that promotes the adoption of innovation, and sometimes it can even be detrimental to the adoption of new products.
Though there have been queries regarding the existence of a country-wide common culture, these assertions do not hold as there are numerous articles regarding how a society's culture influences its members. National culture differences are engrained from an early age and are learned from their parents [17],[5].

\section{Empirical Review}

Global proliferation among countries has led to the demand for managerial research on international diffusion. However, this call was answered to a certain extend by research focused on culture and within-country diffusion of products and services [10], [21]. In this session, the researcher discusses the various drivers of diffusion of innovation.

Culture plays a vital role in innovation which is one of the critical drivers of economic growth and competitiveness of a country, and it's found to be true in research done by [33] where the researchers assessed the relationship between cultural dimensions with its innovativeness from a national perspective. The study used Hofstede's dimensions to measure national culture and Global Innovative Index (GII). The results indicate that national culture has a strong association with the degree of innovation.

A study in a multi-cultural context, on the data taken from 60 nations, found substantial effects of Hofstede's cultural dimensions and demographical variables of managers like age, gender on leadership, and sources of guidance in an organization. The demographic influence on leadership is stronger in individualistic and low power distance countries than elsewhere [35].

Though culture is one of the most researched aspects about the diffusion of innovation, other studies prove that culture alone does not determine the espousal of new products; factors like economic development, ability to purchase new products like information access plays a vital role in the adoption process [7]. Another study done on the adoption of internet banking found that ease of use, relative advantage as the major factors that contribute to adoption [49]. Relative advantage and compatibility were significant influencers in policy adoption in health education intervention [32].

Research on consumer acceptance of the new technologies emphasized that marketing efforts educating consumers on the usefulness and suitability of new technologies like mobile banking in their lifestyles could positively impact the acceptance rate [46]. However, cost and risk also influence the adoption of such technologies. Similar results were found in another study conducted in 
India where consumers' acceptance of mobile commerce was studied. India being a budding market in terms of mobile usage, perceived usefulness, and ease of use were the key drivers; besides, social influence was also found to be one of the drivers; whereas perceived risk harmed the adoption of m-commerce [40]. Consumer lifestyle factors like self-congruence aid in the adoption of new technology, conversely factors like perceived complexity and perceived security were found to be factors that promote resistance. Environmental factors like government scrutiny and uncertainty also cause resistance to the diffusion of innovation [8].

The research conducted by [3], states the existence of regional learning effects on the adoption process, and these effects are prominent in the initial phases of adoption. These learning effects were attributed to the density of adopters and proximity to technology firms. National cultural dimensions like individualism, power distance, and long-term orientation as defined by Hofstede have a positive impact on the adoption of e-governance in a study conducted among 84 nations [48]. One of the studies done on adopting wearable fitness technology found innovativeness to be a significant influencer in the adoption process. The lifestyle of the consumer and technology benefits also enhance the adoption process [37]. [31] provide evidence that early adopters of photovoltaic systems are driven largely by environmental concerns and technology viability whereas late adopters are driven mainly by economic gains.

Other than culture, user compatibility, or the degree of innovation; another aspect that would influence the diffusion of innovation is the economic conditions which include the institutional environment. Research done on the World Economic Forum's Global Competitiveness Report on developed and developing countries posits that political instability and lack of pro-business reforms deter innovation culture in a nation [1].

Demographical variables like race and religion are key factors that influence the acceptance of new products/ technologies. Openness to change has a positive influence on consumer innovativeness and acceptance however religiosity and ethnicity have an opposing effect on openness and consumer innovativeness [24]. Conventionally, opinion leaders play a key role in the spread of innovation [34]; however, [10], in their study posits a new hybrid category of users emerging from the 'Innovator' and 'Early Adopter' categories which they named as 'Leading edge opinion leaders'. This study demonstrates that the new hybrid category is willing to acquire products at a premium and is highly vocal about the products to their peer groups.

\section{Methodology}

The study involved descriptive research. The research involved gathering and reviewing past works of literature to understand the factors of diffusion of innovation. The reason for differential innovation adoption rates in different countries was also studied. Cues from this investigation were used to construct the questionnaire for this study. The data for the research was collected through a selfadministered questionnaire via online mode using web forms. The target population for this research was undergraduate students from three countries Croatia, India, and Sri Lanka.

The questionnaire was designed keeping in mind the target population, and it follows a logical sequence to avoid any bias and misperception. The questionnaire consists of questions about demographic variables like age, country, and the second part consists of questions on their selfassessment on the adopter category they belong. Since the questionnaire was administered in the English language, students who could read and comprehend English could only be selected. Since it was challenging to choose such students, particularly in Croatia, the researchers resorted to snowball sampling.

Snowball sampling is a non -probability sampling technique in which the initial few respondents are selected by the researcher, and the subsequent respondents are chosen by the current subjects through referral [23]. This sampling technique is proper when samples with a specific trait have to be found. There was an almost equal representation of students from the three countries, with $37.2 \%$ Indian students, $30.2 \%$ Croatian students, and $32.4 \%$ Sri Lankans participating in the study. The average age of the respondents was 23.2 years. Previous research rationalizes the use of young consumers to understand the innovation adoption behaviour [22]. Hence the use of students to study the spread of innovation is justified.

Statistical Package for the Social Sciences (SPSS) software package was used for analysing data and conducting correspondence analysis. Correspondence analysis is a multidimensional scaling technique that provides the relative relationship between two groups of variables given in the rows and columns of the contingency table [23]. It provides a sensory map that allows visualization of the similarities and differences between data in the contingency data in a low 
dimensional space [14]. The distance between the category points in the plot reveals the relationships between the categories. For instance, the proximity of the categories in the map denotes their close relationships.

In correspondence analysis, data is processed mathematically by the following derivations [15]. The proportion matrix, $\mathbf{P}$, is derived by dividing the elements of $\mathbf{K}$ by the total of all numbers in $\mathbf{K}$. Mathematically,

$$
\text { (1) } \mathrm{P}=\left\{p_{i j}\right\}=\left\{\frac{k_{i j}}{\mathrm{k}}\right\}
$$

The distances, $d_{i}$, and the column distances, $d_{j}$ used in correspondence map is derived from equation (2) and (3).

$$
\begin{aligned}
& \text { (2) } d_{i}=\sum_{j}\left[\frac{1}{p_{j}}\right]\left[\frac{p_{i j}}{p_{i}}-p_{j}\right]^{2} \\
& \text { (3) } d_{j}=\sum_{i}\left[\frac{1}{p_{i}}\right]\left[\frac{p_{i j}}{p_{j}}-p_{i}\right]^{2}
\end{aligned}
$$

\section{Findings of the Study}

This study used correspondence analysis which is a technique for graphically displaying a two-way table by calculating coordinates representing its rows and columns. It helps to determine the relative relationship between the categorical variables and it works by decomposing a matrix of chi-squared values derived from the rows and columns of the expression matrix.

The two variables considered in this study are 'country' and 'stages of diffusion of innovation'. Here the five stages of diffusion of innovation innovators, early adopters, early majority, late majority, and laggards as proposed by [37] are represented in the column and the countries India, Sri Lanka, and Croatia in the row.

Table 1 Correspondence Table

\begin{tabular}{|l|l|l|l|l|l|l|}
\hline \multirow{2}{*}{ Country } & \multicolumn{2}{l}{ Stages of Diffusion of Innovation } & \multicolumn{2}{l|}{} \\
\cline { 2 - 7 } & Innovator & Early Adopter & Early Majority & Late Majority & Laggard & Active Margin \\
\hline India & 11 & 26 & 25 & 4 & 3 & 69 \\
\hline Croatia & 6 & 17 & 22 & 10 & 1 & 56 \\
\hline Sri Lanka & 9 & 22 & 20 & 4 & 5 & 60 \\
\hline Active Margin & 26 & 65 & 67 & 18 & 9 & 185 \\
\hline
\end{tabular}

Source: Survey Data

Table 1 shows the correspondence table, which displays the frequency for each category of each variable; it is essentially a cross-tabulation frequency table. From the above table, it can be noted that the majority of respondents $(42 \%)$ in the innovator category were Indians followed by Sri Lanka and Croatia. Similarly, Indians also top the Early Adopter and Early Majority category with $40 \%$ and $37 \%$ respectively. Which in turn can be inferred as the majority of the Indians considered themselves to be in the 'Early Adopter' and 'early majority phase of diffusion of innovation. Sri Lankans on the other hand belonged to the Early Adopter and Early Majority categories. Compared to the other two countries, the number of Early Adopters was least in Croatia and also, they toped

\begin{tabular}{|c|c|c|c|c|c|c|c|c|}
\hline \multirow[b]{3}{*}{ Dimension } & \multirow{3}{*}{$\begin{array}{l}\text { Singular } \\
\text { Value }\end{array}$} & \multirow[b]{3}{*}{ Inertia } & \multirow{3}{*}{$\begin{array}{l}\text { Chi } \\
\text { Square }\end{array}$} & \multirow[b]{3}{*}{ Sig. } & \multicolumn{2}{|c|}{ Proportion of Inertia } & \multicolumn{2}{|c|}{ Confidence Singular Value } \\
\hline & & & & & Accounted & & Standard & Correlation \\
\hline & & & & & for & Cumulative & Deviation & 2 \\
\hline 1 & .214 & .046 & & & .887 & .887 & .074 & .083 \\
\hline 2 & .076 & .006 & & & .113 & 1.000 & .077 & \\
\hline Total & & .052 & 9.562 & $.297^{\mathrm{a}}$ & 1.000 & 1.000 & & \\
\hline
\end{tabular}
the Late Majority category with $55 \%$ respondents.

Table 2 Summary Table

Source: Survey Data 
Table 2 displays the summary table where the rows represent the calculated latent variables, and the columns represent various statistics and quantities associated with those latent variables. The vital data to note at this point is the cumulative column under the proportion of inertia. The inertia column indicates the breakdown of the inertia of each dimension to the total inertia. This gives the proportion of the accounted for variability (inertia) attributed by that latent variable, so the first latent variable accounts for $88.7 \%$ of the total variability. With the single dimension, $88.7 \%$ of the inertia is explained, and a cumulative of $99.7 \%$ is explained by the first and second dimensions. It is noted that though two dimensions were derived, only one- dimension accounts for a meaningful proportion of the total inertia value hence can limit the number of latent variables to 1 . Here the chi-square test is done to test the hypothesis that the total inertia value is not different from zero. The chi-square statistic is 9.56 with a significance value greater than 0.05 , which indicates that the total inertia value is not significantly different from zero. Finally, to look at the correlation matrix, the latent variables are to be orthogonal indicating that the variables are uncorrelated with each other. From table 2 it can be noted that the correlation is 0.083 , indicating a low correlation.

Table 3 Overall Row Point Table- Country

\begin{tabular}{|c|c|c|c|c|c|c|c|c|c|}
\hline \multirow[b]{3}{*}{ Country } & \multirow[b]{3}{*}{ Mass } & \multicolumn{2}{|c|}{$\begin{array}{l}\text { Score in } \\
\text { Dimension }\end{array}$} & \multirow[b]{3}{*}{ Inertia } & \multicolumn{5}{|c|}{ Contribution } \\
\hline & & \multirow[b]{2}{*}{1} & \multirow[b]{2}{*}{2} & & \multicolumn{2}{|c|}{$\begin{array}{l}\text { Of Point to Inertia of } \\
\text { Dimension }\end{array}$} & \multicolumn{3}{|c|}{$\begin{array}{l}\text { Of Dimension to Inertia of } \\
\text { Point }\end{array}$} \\
\hline & & & & & 1 & 2 & 1 & 2 & Total \\
\hline India & .373 & -.243 & .328 & .008 & .103 & .524 & .607 & .393 & 1.000 \\
\hline Croatia & .303 & .698 & -.049 & .032 & .688 & .009 & .998 & .002 & 1.000 \\
\hline Sri Lanka & .324 & -.372 & -.331 & .012 & .209 & .466 & .779 & .221 & 1.000 \\
\hline $\begin{array}{l}\text { Active } \\
\text { Total }\end{array}$ & 1.000 & & & .052 & 1.000 & 1.000 & & & \\
\hline
\end{tabular}

a. Symmetrical normalization

Source: Survey Data

Table 3 displays the overview row points table, values that allow the research to evaluate how each row contributes to the dimensions and how each dimension contributes to the rows. India and Sri Lanka contribute more to dimension one. Croatia lies very close to the origin and hence cannot be categorized into any dimension. In table 3 , the mass column refers to the proportion of the category in the sample and is taken as a measure of the importance of that category amongst the whole sample. The column 1 and column 2 values under the 'Score in Dimension' are the coordinates of the category on the respective latent variable. So, India has a score of -0.243 on dimension 1 and 0.328 on dimension 2. The inertia column indicates the relative effect that category is having upon the solution as a whole. Here the inertia is relatively small and no particular category is dominating the solution.

Table 4 Overall Column Point Table-Diffusion Categories

\begin{tabular}{|c|c|c|c|c|c|c|c|c|c|}
\hline \multirow{3}{*}{$\begin{array}{l}\text { Diffusion of } \\
\text { Innovation }\end{array}$} & \multirow[b]{3}{*}{ Mass } & \multicolumn{2}{|c|}{$\begin{array}{c}\text { Score in } \\
\text { Dimension }\end{array}$} & \multirow[b]{3}{*}{ Inertia } & \multicolumn{5}{|c|}{ Contribution } \\
\hline & & \multirow[b]{2}{*}{1} & \multirow[b]{2}{*}{2} & & \multicolumn{2}{|c|}{$\begin{array}{l}\text { Of Point to Inertia of } \\
\text { Dimension }\end{array}$} & \multicolumn{3}{|c|}{$\begin{array}{l}\text { Of Dimension to Inertia of } \\
\text { Point }\end{array}$} \\
\hline & & & & & 1 & 2 & 1 & 2 & Total \\
\hline Innovator & .141 & -.329 & .166 & .004 & .071 & .051 & .917 & .083 & 1.000 \\
\hline Early Adopter & .351 & -.189 & .081 & .003 & .059 & .030 & .939 & .061 & 1.000 \\
\hline Early Majority & .362 & .128 & .096 & .002 & .028 & .044 & .832 & .168 & 1.000 \\
\hline Late Majority & .097 & 1.172 & -.365 & .030 & .624 & .170 & .967 & .033 & 1.000 \\
\hline Laggard & .049 & -.981 & -1.052 & .014 & .218 & .705 & .709 & .291 & 1.000 \\
\hline Active Total & 1.000 & & & .052 & 1.000 & 1.000 & & & \\
\hline
\end{tabular}

Source: Survey Data 
In Table 4 the contribution of the 'Dimension to Inertia of Point' column shows the role each dimension plays in each column. Early adopters and the late majority contribute the most to dimension one and laggards contribute to dimension 2. For the Early Majority category both the scores in the dimension have positive magnitude hence will be positioned in the positive segment of the spatial map. Laggard has both negative magnitude and other categories have at least one negative magnitude hence will be placed accordingly in the map. Again, from the inertia column, no particular category seems to dominate the solution.

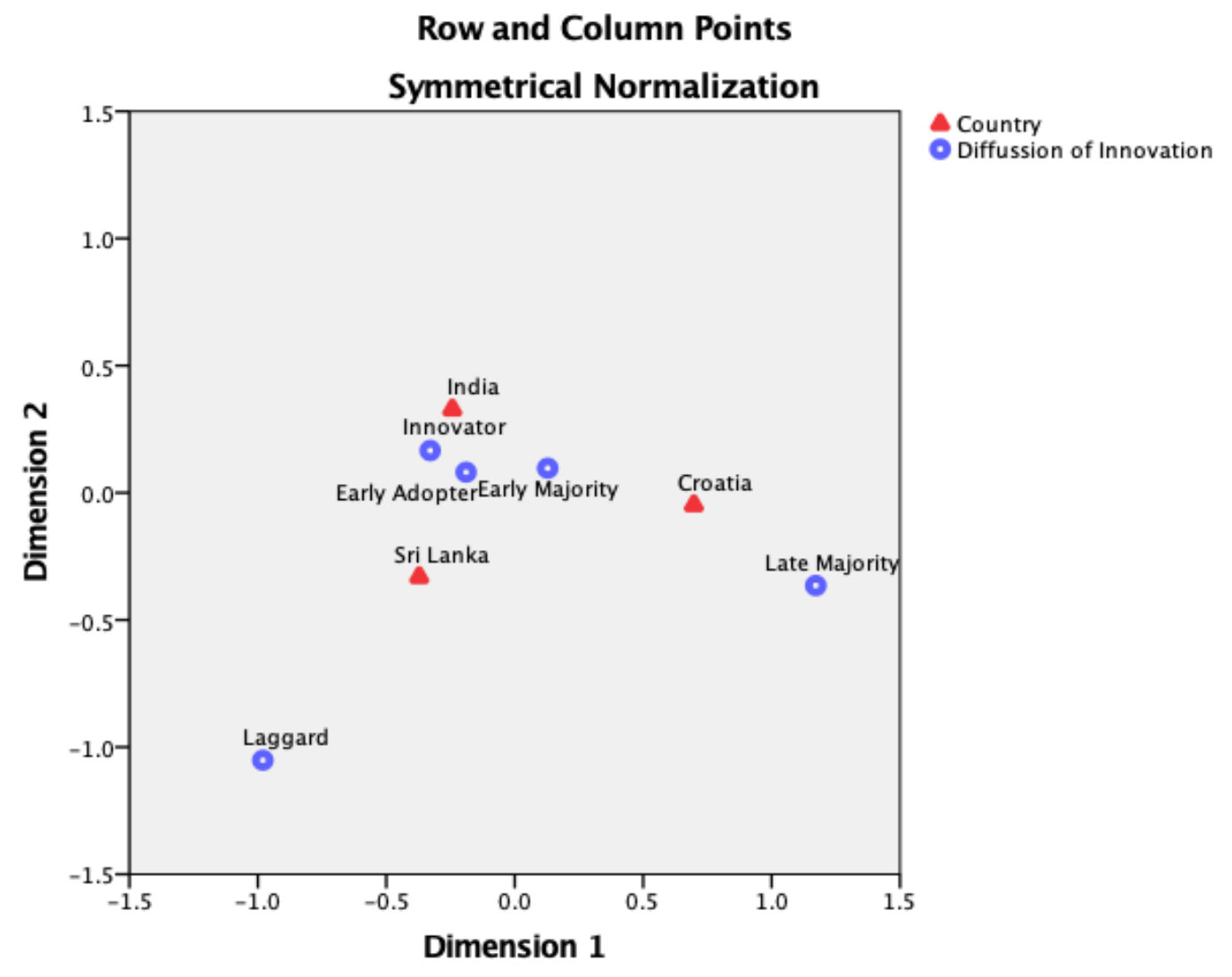

Figure 1 Correspondence Map [Source: Data Analysis]

Figure 1 depicts the correspondence map with each category score plotted against the two dimensions simultaneously for both the stages of diffusion of innovation and country- India, Sri Lanka and Croatia. Two South Asian countries and the other a European Union country. As both variables can be seen in terms of the latent variables, any proximity between categories of either variable on the biplot is interpretable as more substantive proximity. For instance, in this spatial map, India is seen in close proximity to Innovator and Early Adopter category, whereas Sri Lanka is seen placed close to the Early Adopter and Early Majority category. Hence we could infer that youth in India perceives themselves to be in 'innovator' and 'early adopter categories in comparison to the other two countries. Whereas Croatian students were in the 'late majority stage, and Sri Lankan youths were midway between early adopters and early majority categories.

\section{Discussion}

Indeed, globalization has facilitated the spread of know-how and technology across borders. The spreading of technology matters particularly in improving the productivity and economic growth of a country. It is a crucial driver in improving the income and standard of living in a society [42]. Technology transfer across countries can transpire in many ways. Firms try to exploit overseas markets to take advantage of their competitive position. Evidence proves that global collaborations are also one way of technology transfer. High capital 
investments have led firms in developed countries to have a mutually beneficial dependence relationship with emerging countries. The availability of a competent workforce and market potential has resulted in the offshoring of many $\mathrm{R} \& \mathrm{D}$ centres to emerging economies which has benefitted them a lot [42].

Although all the three countries selected for this study are generally categorized as developing nations, research posits that various factor account for the different adoption rates across countries. Other than culture, economic factors like the nation's wealth and opportunities and disposable income affect the consumers' ability to spend.

Being an emerging market with over one billion population, India has been an attractive destination for multi-national firms. Other than this vast potential, another charm that has lurked multinational businesses to start their operations in India, is the rising middle class. India's middle class, though is $20 \%$ now, is expected to reach 41 $\%$ of the population by 2030 [25].

The country's large talent pool has made India a global centre for outsourcing, and this has provided Indian households with more significant disposable income and, most importantly, an 'irreversible awakening of the aspirations of a billion people' [44]. The increasing material centric consumption patterns among the middle-income Indians [5] could be one reason why India was in the 'Innovator' and 'Early Adopter' categories. The economic index like country's Gross Domestic Product (GDP) also validates this finding- according to the World Bank 2019 report, India had a GDP of $4.18 \%$, Croatia $2.94 \%$, and Sri Lanka $2.3 \%$ [41]. A previous study posits that there is a growing desire for luxury consumption among the Indian middle class which in turn could drive domestic consumption [6]. This result is reflected in the 'Households and Non-Profit Institutions Serving Households Final consumption expenditure' (as a percentage of annual growth) which places India on top with $5.3 \%$ over Croatia $(3.5 \%)$ and Sri Lanka (2.9\%) in 2019 (The World Bank, 2021). Also, in terms of the consumer confidence index, India tops the list among the three [41].

Both India and Sri Lanka have a heritage of ethnic, religious, intellectual, and linguistic

\section{Managerial Implications}

Today, the world's economies face crucial challenges in terms of reduced growth, recession, mounting unemployment, etc. Countries require collaboration. On exploring the cultural dimensions of Sri Lanka through the lens of Hofstede's cultural dimensions, it could be seen that both India and Sri Lanka are very close in many of the dimensions. However, Sri Lanka scores higher than India in power distance and uncertainty avoidance. Whereas in Individualism and long-term orientation, India scores high than Sri Lanka. Also, India is found to be a more masculine society i.e., a society is driven by competition, success, and achievement whereas the feminine dimension was more dominant in Sri Lanka where the quality of life is the sign of success and standing out from the crowd is not admirable This justifies why Sri Lankan students perceived themselves to belong to categories midway to 'Early Adopter' and 'Early Majority.

A sociocultural analysis conducted in the Balkan countries using the Grey accounting dimensions derived from Hofstede's value dimensions found Croatia to score least in the dimensions like Conservatism, Uniformity, and Secrecy when compared to the other Balkan states like Bulgaria, Romania, Serbia, Slovenia. Yet, Croatia scored higher in these dimensions than their neighbouring EU countries like Austria and Italy [4]. Conservatism denotes the lack of optimism in the society, uniformity signifies lack of flexibility and secrecy implies lack of transparency in the system. Previous research among EU countries suggests that countries with high Individualism, Long-term orientation, and low power distance and uncertainty avoidance demonstrate a greater propensity to adopt novel technologies [2]. Taking into account Hofstede's cultural dimensions, Croatia scores low in Individualism and high on Power Distance. Also, Croatia has high Uncertainty Avoidance which means that these cultures have stiff rules and are intolerant to unorthodox behaviour- lack of acceptance of innovation as they give more focus on security (Hofstede's Insights). On the contrary, though it scores high on Power Distance, India's score on Uncertainty Avoidance is 40 which is far lower in comparison to the world average of 65 . This implies that India is more tolerant of uncertainty and accepts shortfalls [19]. Hence this study results that demonstrate that Indian youth are quicker to adopt innovation than Croatian youth is justified.

sustainable sources of growth to recover from this situation. The introduction of a new process or a modified product or service plays a significant role 
in boosting the economy. However, innovation has different implications for different economies like developing, emerging, and developed [37].

According to [30], innovation for development materialise in five phases. Firstly, the awareness of the contributions of innovation to all the sectors of the economy is quintessential to kick start the change process. Innovation not only in high technology areas but in sectors like services, agriculture that are crucial in the case of emerging countries.

The second phase is when domestic economies open up for foreign competitors whereby facilitating consumer access to foreign products and technologies. Trade openness also leads economies to specialise in sectors where they have a competitive advantage. For instance, India's software industry is the outcome of opening up national boundaries.

The third phase of innovation progress in a country is 'inclusive innovation'- or innovation for the lower or middle class. Imitating someone else's system might not work for all. It will be a mistake to believe that what works in one context will work in another. In emerging and developing countries where the economic disparity is high, adoption of innovation requires adapting to address the specific local challenges. Frugal innovation drives grass-root entrepreneurship which is essential for the sustainable development of an emerging economy. For example, the success of Nano car and mobile banking services in India illustrations the principle of 'adoption with adaptation' in emerging economies [32].

Fourthly, Higher education and human capital play a significant role in innovation development and adaptation. Investment in higher skill development and job creation go hand in hand.

Fifthly, information and communication technologies (ICTs) empower innovators and scientists from the emerging world to access scientific or business knowledge from all around the world more easily and help entrepreneurs to reach more customers and widen their potential market.

Another study conducted among the developing countries found that knowledge diffusion is expedited by the openness of the economy, foreign direct investments. The study posits that empowering the bottom of the pyramid can positively impact the diffusion of innovation [47].

In congruence to these findings, there is evidence to believe that the reason for Indian students to belong to the innovator and early adopter categories is owing to the factors like the openness of the Indian economy, emergence of the middle-income class, and availability of skilled labour. This is one of the reasons why India is said to be a rising global hub of innovation and that not just means hub for software development, rather in the pharmaceutical sector where Indian pharmaceutical companies are contracted researchers developing products for western firms [36].

India is the second most connected nation in the world in terms of internet connectivity, with even the rural population having access to smartphones with one of the low-cost mobile data plans has exposure to the different brands through social media. Being connected to the internet, makes communication of the new products and services much easy which in turn enhances the adoption process. E-Commerce sites and social media advertisements play a significant role in the adoption of new products and services in India. The results of the study indicate that Indian youth perceive themselves to be in Innovator and Early adopter categories, probably because of their awareness of the new products which makes them take reasonable risk.

Marketers will find this result interesting as it provides insights into the different strategies firms have to adapt to order to capture the respective markets. Indian being Innovators and Early Adopters are quick to adopt new products and are opinion leaders. Driven by internet connectivity and e-commerce, social media marketing is a big thing in India. Marketers have to invest in social media marketing to reach the youth. Firms are collaborating with e-commerce platforms like Flipkart and Amazon to sell their products; for instance, One plus the Chinese smartphone manufacturer has captured the Indian market through their collaboration with Amazon [20].

Though Sri Lanka is behind India in terms of the Consumer Spending index, research does indicate that Sri Lanka is firming up to international markets and brands [11]. Whereas in Croatia, the youth perceive to belong to the late majority category. This could mean that marketers have to be careful while introducing new services and products as the late majority are sceptical of changes. Research posits Croatian consumers to be value-orientated and most often purchase products for their functionalities [13],[9]. Another study, confirms that Croatians are not inclined to buy exclusively branded products as they do not perceive branded products to have more quality [45]. This could be challenging as brands have to develop their branding strategy based not just on the snob value rather on functionality, and brands should be able to emotionally connect to their audience. 


\section{Limitations and Future Research Directions}

One of the major limitations of the study is the relatively small sample size of the respondents. Though there is almost equal representation from all three countries, the sample need not be representative of the population.

The use of an online mode for data collection, whereby participants themselves decide whether to participate in the survey also presents another shortcoming. Also, since the questionnaire was in English language and was administered among students from Croatian and Sri Lankan which are non- English-speaking countries, researchers cannot be sure if there were any lack of clarity in the questions.

Another significant limitation is concerning the sampling technique administered. In snowball sampling, as respondents are referred by previous subjects, the representativeness of the sample cannot be guaranteed. Though the respondents might share similar traits or characteristics, the sample that the researcher will obtain may be only a small subgroup of the entire population.

An additional limitation is that this study doesn't focus on the diffusion of any particular service or product, but it's a general self-evaluation of respondents about the adopter category they belong to.

For future research, the researchers recommend a larger sample size with appropriate representation from each country. Also, in the future, the study should focus on the diffusion of a particular service or product which has already been introduced in the market or a service or product which has been newly introduced. This will provide a better understanding of the different adopter categories. Also, research can be expanded to include other age groups and working class. Comparative analysis can also be done to understand if consumer preference and attitude vary according to age group their profession and income group.

\section{Conclusion}

Opening up of trade has benefitted economies at large, particularly economies with established or growing customer base. Such markets are important as it provides an opportunity to global firms to overcome market saturation in the home country and establish themselves in a different country. The rising middle class with disposable income, internet penetration, consumer spending, and political stability - all these factors increase market lucrativeness. India's success lies in the fact that it is the source of a talented pool of workforce who is determined to scale greater heights. This aspirational middle class offers enormous potential for marketers. Research suggests that the growing material-centric behaviours of the Indian middleincome society have led to conspicuous consumption. This study can provide insights to marketers regarding the success and failure of product/service diffusion. It also would tell the theme regarding the pace of adoption and the strategies to follow while introducing new products.

Croatian consumers are price-sensitive and are not open to new brands entering the market as their consumer confidence in the economy was bit due to the recession in the economy. This could have been why Croatia has been lagging in the adoption of innovation despite being a member of the EU. However, research cites that Croatian consumer are slowly gaining confidence in the economy and opening up to the European materialistic culture, and consumer confidence in the economy is also improving.

\section{References:}

[1] Allard, G., Martinez, C. A., \& Williams, C. (2012). Political instability, pro-business market reforms and their impacts on national systems of innovation. Research Policy, 41(3), 638-651.

[2] Arslan, A. (2009). Cross Cultural Analysis of European E-Government Adoption. Munich Personal RePEc Archive (MPRA).

[3] Baptista, R. (2000). Do Innovations Diffuse faster within Geographical Clusters? International Journal of Industrial Organization, 18, 515-535.

[4] Borker, D. R. (2015). Sociocultural IFRS Value Analysis in Five Balkan Countries. Journal of Accounting and Finance, 15(5), 66-75.

[5] Chacko, P. S., Prashar, S., \& Ramanathan, H. N. (2018). Assessing the relationship between Materialism and Conspicuous Consumption: Validation in the Indian context. Asian Academy of Management Journal, 23(2), 143-159.

[6] Chacko, P. S., Ramanathan, H. N., \& Prashar, S. (2019). Desire and likeliness to buy luxury products: mapping perceptions using multidimensional scaling. 
International Journal Indian Culture and

Business Management, 18(2), 123-136.

[7] Chandrasekharan, D., \& Tellis, G. J. (2008). Global Takeoff of New Products: Culture, Wealth or Vanishing Differences?

Marketing Science, 1-17.

[8] Chouk, I., \& Mani, Z. (2019). Factors for and against resistance to smart services: role of consumer lifestyle and ecosystem related variables. Journal of Services Marketing, 449-462.

[9] Dominici, G., Matić, M., Abbate, T., \& Di Fatta, D. (2016). Consumer attitude toward using smart shopping carts: a comparative analysis of Italian and Croatian consumer attitudes. International Journal of Electronic Marketing and Retailing, 7 (3), 229-244.

[10] Douglas, S. P., \& Craig, C. (1992). Advances in international marketing. International Journal of Research in Marketing, 9(4), 291-318.

[11] Fashionating World. (2018, July 4). Sri Lanka Strengthening its presence in global luxury fashion. Retrieved from fashionatingworld.com: https://www.fashionatingworld.com/new12/sri-lanka-strengthening-its-presence-inglobal-luxury-fashion

[12]Franke, N., Hippel, E., \& Schreier, M. (2006). Finding commercially attractive user innovations: Journal of Product Innovation Management, 23, 301-315.

[13]Fox, J. (1999). Croatian and European Consumerism. Društvena istraživanja: Journal for General Social Issues, 8(4 (42)), 623-633.

[14]Greenacre, M. (2010). International Encyclopedia of Education (3 ed.). (E. B. Penelope Peterson, Ed.) Science Direct.

[15]Greenacre, M. (2017). Correspondence Analysis in Practice (Vol. 3). Barcelona: CRC Press, Taylor \& Francis Group.

[16]Hassan, S., Mourad, M., \& Tolba, A. H. (2010). Conceptualizing the influence of lead users and opinion leaders on accelerating the rate of innovation diffusion. International Journal of Technology Marketing, 5, 203-219.

[17]Hofstede, G. (2011). Dimensionalizing Cultures: The Hofstede Model. Online Readings in Psychology and Culture, 2(1).
[18]Hofstede, G. (2012). National Cultures, Organizational Cultures, and the Role of Management. In Values and Ethics for the for the 21st Century (pp. 385-404). BBVA.

[19]Hofstede's Insights. (n.d.). Hofstede's Insights. Retrieved April 6, 2021, from https://www.hofstede-insights.com/

[20]IBEF. (2020, December 2). Indian Brand Equity Foundation. Retrieved April 21, 2021, from https://www.ibef.org/industry/advertisingmarketing-india.aspx

[21]Kumar, V. (2014). Understanding Cultural Differences in Innovation: A Conceptual Framework and Future Research Directions. Journal of International Marketing, 22(3).

[22]Lazarevic, V. (2012). Encouraging brand loyalty in fickle generation $Y$ consumers. Young Consumers, 13(1), 45-61.

[23]Malhotra, N. K., \& Dash, S. (2011). Marketing Research (6 ed.). New Delhi, India: Pearson.

[24]Mansori, S., Sambasivan, M., \& Md-Sidin, S. (2015). Acceptance of novel products: the role of religiosity, ethnicity and values. Marketing Intelligence and Planning, 39-66.

[25]McKinsey Global Institute. (2007). The Bird of Gold': The Rise of India's Consumer Market". San Francisco: McKinsey \& Company.

[26]Minkov, M., \& Hofstede, G. (2012). Hofstede's Fifth Dimension: New Evidence From the World Values Survey. Journal of Cross-Cultural Psychology, 43(1), 3-14.

[27]Minkov, M., \& Hofstede, G. (2014). A replication of Hofstede's uncertainty avoidance dimension across nationally representative samples from Europe. International Journal of Cross-Cultural Management, 14(2), 161-171.

[28]Moua, M. (2012). Leading with Cultural Intelligence. Saylor Foundation.

[29]National Research Council. (1988). Globalization of Technology: International Perspectives. The National Academies Press.

[30]OEDC. (2012). Innovation for development. Directorate for Science, Technology and Industry.

[31]Palm, A. (2020). Early adopters and their motives: Differences between earlier and 
later adopters of residential solar photovoltaics. Renewable and Sustainable Energy Reviews.

[32]Pankratz, M., Hallfors, D., \& Cho, H. (2002). Measuring perceptions of innovation adoption: The diffusion of a drug prevention policy. Health Education Research, 17(3), 315-326.

[33]Prim, A. L., Filho, L. S., Zamur, G. A., \& Serio, L. C. (2017). The relationship between national culture dimensions and degree of innovation. International Journal of Innovation Management, 21(1).

[34]Rogers, E. M. (2003). Diffusion of Innovations, 5th Edition. The Free Press.

[35]Smith, P. B., \& Peterson, M. F. (2005). Demographic effects on the use of vertical sources of guidance by managers in widely differing cultural context. International Journal of Cross-Cultural Management, $5(1), 5-26$.

[36]Strategic Direction. (2013). India Emerging as Innovation Hub? Dead-end jobs or a hot bed for imaginative thinking. Emerald Publishing Limited.

[37]Talukdu, M. S., Chiong, R., Bao, M., \& Malik, B. H. (2019). Acceptance and use predictors of witness wearable technology and intention to recommend- An empirical study. Industrial Management and Data Systems, 119(1), 170-188.

[38]Tanchua, J., \& Shand, D. (2016, August 3). Emerging Markets May Offer the Most Potential for the World's Largest ConsumerFocused Companies. Retrieved from S \& P Global:

https://www.spglobal.com/en/researchinsights/articles/emerging-markets-mayoffer-the-most-potential-for-the-worldslargest-consumer-focused-companies

[39]Tellis, G. J., Stremersch, S., \& Yin, E. (2003). The International Takeoff of New Products: The Role of Economics, Culture, and Country Innovativeness. Marketing Science, 151-271.

[40]Thakur, R., \& Srivastava, M. (2013). Costumer usage intention of mobile commerce in India: An empirical study. Journal of Indian Business Research, 52-72.

[41]The Global Economy. (n.d.). Business and Economic data for 200 countries. Retrieved from The Global Economy:

https://www.theglobaleconomy.com/compar e-countries/

[42]The International Monetary Fund. (2018, April). World Economic Outlook: Cyclical Upswing, Structural Change. Washington, DC, USA.

[43]The World Bank. (2021, 03 09). The World Bank. Retrieved from https://www.worldbank.org/en/who-we-are

[44]Venkatesan, R. (2003). Conquering the Chaos: Win in India, Win Everywhere. Harvard Business Review Press.

[45]Vraneševića, T., \& Perićb, N. (2020). Comparative analysis of consumer attitudes in Croatia and Serbia according to domestic and foreign brands. Economic Research, 33(1), 68-86.

[46]Wessels, L., \& Drennan, J. (2010). An investigation of consumer acceptance of $\mathrm{M}$ banking. International Journal of Bank Marketing, 547-568.

[47]Zanello, G., Fu, X., Mohnen, P., \& Ventresca, M. (2015). The creation and diffusion of innovation in developing countries: A systematic literature review. Journal of Economic Surveys 30(5), 884912.

[48]Zhao, F. (2011). The impact of natural culture on e- government development: a global study. Internet Research, 21(3), 362380.

[49]Zolait, A. S. (2008). Incorporating the Innovation Attributes Introduced by Rogers into Theory of Reasoned Action: An Examination of Internet Banking Adoption in Yemen. Computer and Information Science, 1(1), 36-51.

\section{Contribution of individual authors to the creation of a scientific article}

Pearly Saira Chacko- writing - original draft, investigation,editing and supervision.

Hareesh N Ramanathan - methodology, review, investigation, data analysis and supervision.

Berislav Andrlic - methodology and review. 
Sources of funding for research presented in a scientific article or scientific article itself

Not applicable

\section{Creative Commons Attribution License 4.0 (Attribution 4.0 International, CC BY 4.0)}

This article is published under the terms of the Creative Commons Attribution License 4.0

https://creativecommons.org/licenses/by/4.0/deed.en US 